\title{
Identification of safety hazards and their sources in tram transport
}

\author{
Jacek Szmagliński ${ }^{1, *}$, Stawomir Grulkowski ${ }^{1}$, and Krystian Birr ${ }^{1}$ \\ ${ }^{1}$ Gdańsk University of Technology, Gabriela Narutowicza 11/12, 80-233 Gdańsk
}

\begin{abstract}
Both in Poland and in most countries of the European Union, the tram infrastructure is extensively expanding. Contemporary low-floor trams are constructed according to different technical assumptions than typical railway vehicles or high floor trams. In Poland such vehicles rides often on lines designed according to standards developed to the classical vehicles. At the same time, the intensity of road traffic and the number of people using cycling are increasing in cities, which causes into a greater number of dangerous situations at the contact points between various modes of transport. The scope of this article is the analysis of safety hazards in tram transportation and indication of methods for their reduction. It will be a specific analysis of the risk occurring in tram transport. The article presents a division and description of factors that pose a safety hazard to tram traffic. Threats were divided due to the reason for its occuring and due to its effects. The reasons were divided into Human Factor - Vehicle - Road - Traffic - Surroundings. Based on the analysis conducted on the tram network in Gdańsk and on the used rolling stock, the main safety hazards of tram traffic were identified.
\end{abstract}

\section{Development of tram transport and related hazards}

After decades of stagnation, tram transport is currently undergoing a period of revival. The tram infrastructure is being intensively expanded. Passengers expect ever higher travel comfort, shorter travel times, an ever greater sense of safety and increased reliability from this mode of transport.

Growing passenger expectations are a source of increasingly complex challenges, including that of traffic safety. Contemporary low-floor trams are constructed according to different technical requirements than in the past. By comparison to classic high-floor trams, they are faster, heavier and have a higher centre of gravity. In Poland the low-floor vehicles run most often on lines designed according to standards developed in the time of classic vehicles use (high-floor tram cars modelled on PCC trams). At the same time, the road traffic volume and the number of cyclists are increasing in cities which translates into a greater number of dangerous situations at the interface of these various modes of transport.

The purpose of this article is to indicate the hazards in tram traffic, their general analysis, and an attempt to indicate methods to reduce them.

\footnotetext{
* Corresponding author: jacszmag@pg.edu.pl
} 


\section{Methods of assessment and classification of hazard in transport}

Many aspects of the definitions of hazard, accidents and risk in rail transport are included in EU documents [1-3]. According to the nomenclatures contained therein, hazard describes a situation that can lead to an accident. In turn, an "accident" means an unwanted or unintentional, sudden event or series of events that have severe consequences. An incident is any event, other than an accident, associated with the rail traffic and affecting its safety.

Consequently, the definition of the "risk" is the frequency of accidents and incidents leading to damage (caused by the hazard) and the degree of severity of this damage, which, in practical terms, leads to the conclusion that "risk" is a potential possibility of hazard occurrence [4].

The operation of each technical system, including the tram system, refers to the maintenance system and the usage system [5-7].

The priority objective of the tram system is providing collective passenger transport. Two processes take place then: use and maintenance. In these processes there is a risk of hazard occurrence. There will be a different character of risk in the use of the tram system and different in the process of its operation. It is assumed that during the use passengers, tram personnel and road users, including pedestrians, will be subjected to risk, and during maintenance - technical back-up staff will be at risk. The minimisation of risk is related to the operation of the system - the safety requirements that this system should meet are established. Indeed, the EU Regulations [1] mention two measures of risk: the first is the frequency of accidents and incidents leading to injury, and the second is the severity of the event. Therefore, in the EU nomenclature there are safety indicators in rail transport, such as: number of accidents divided into types, number of injured persons, number of accidents during transport of dangerous goods, number of suicides, number of events preceding accidents related to improper technical condition of infrastructure and running gear of vehicles, as well as operator errors.

So far, comprehensive and detailed research related to risk management in tram transport has not been undertaken. Research in this area concerns only selected hazards or selected groups of safety system elements. The main subject of the research so far has been noise hazard [8-10]. Another problem described widely is the derailment of trams connected with the condition of tracks [11].

Identification of hazards in the tram system is more difficult as the essence of this mode of transport is connecting certain features of road and rail transport. In such a complex and extensive system, it is worth starting the classification of hazards from the original division into hazards resulting from the current use and operation of the system and hazards resulting from maintaining the system's efficiency.

At various levels of transport organisational structures, there are many entities associated with risk management in tram transport:

- Tram drivers and passengers and co-users of the same urban spaces defined by tram network systems;

- Business entities providing tram transport services;

- Manufacturers and repair workshops for trams and tram infrastructure devices;

- Regional and local managements of transport and transport infrastructure;

- Universities, research institutes and transport safety observatories;

- Regional and local governments;

- Central authorities and institutions;

- International organisations [12]. 
Factors that pose a hazard in tram traffic can be divided into the following categories [13], broken down due to the cause (according to the division: Human-Vehicle-RoadTraffic-Surroundings) [14]:

1. Smoke, fire, explosion,

2. Outbreak of panic,

3. Electric shock,

4. Derailment,

5. An accident involving a passenger,

6. Collision between trams,

7. Tram collision with other type of vehicle or pedestrian,

8. Running into an obstacle on the tracks,

9. Other.

\section{Adaptation of methods used in road and rail transport in order to assess safety hazards occurring in tram transport}

The methodology for the assessment of hazards occurring in tram traffic is based on three separate premises:

- assessment of the technical condition during the track inspection (rounds) performed by the authors,

- statistical analyses of accidents and failures occurring on the tram network,

- surveys and interviews conducted among tram drivers.

A particular element of the risk assessment process is hazard detection. This is the most labour-intensive stage and definitely involves the engineering potential of the assessment team. What is required is not only technical knowledge, but also extensive imagination and ability to predict the consequences of observed situations.

The assessment of the condition of tram tracks in Gdansk was conducted according to the rules described in the instructions Id-7 [15] and Id-8 [16]. According to these instructions, the assessment of the technical condition is usually performed by visual inspection, carried out during the rounds of the tracks. During the rounds, which should take place at least once a week on typical tram lines, the condition of the track, points, overhead contact lines and surroundings elements are checked. This type of research allowed to detect hazards related to poor condition of tracks or elements of the tram network in Gdansk.

Statistical analyses of accidents and failures related to tram traffic were conducted. Such analyses should be performed periodically [13] in order to detect locations with a particularly high concentration of dangerous situations and then to evaluate the applied technical and organisational solutions [17]. The research was based on data provided by the tram operator in Gdansk and by the police. The most serious problem encountered during the analyses of such data sets is their low accuracy. Reporting services very often describe an event very generally, often without even providing the exact location. The assessment of the reasons for the occurrence of the event is most often determined on the basis of the fault found (tram driver fault, external fault), there is rarely an in-depth description of cause-andeffect relationships.

Due to the difficulties associated with the detection of the causes of a dangerous situation only on the basis of the analyses of the condition of the track and occurring events, an additional survey was conducted among the tram drivers. 50 tram drivers filled the survey forms. The analysis began with confronting the hazardous locations identified by the drivers with the results of statistical analyses of accidents. Then, the interviews with drivers were carried out, which allowed to determine what elements of infrastructure, rolling stock 
or traffic control system caused an increase in their sense of hazard. The indicated factors can be a source of problems related to the safety of tram traffic.

\section{The division of the tram network in Gdansk due to the identified hazards to tram traffic safety}

After decades of stagnation, tram transport is currently undergoing a period of revival. The tram infrastructure is being intensively expanded. Passengers expect ever higher travel comfort, shorter travel times, an ever greater sense of safety and increased reliability from this mode of transport.

In order to identify hazards and their location on the tram network, an analysis was conducted of databases on events involving tram traffic from 2013-2017 obtained from the managements of tram infrastructure (GZDiZ) and the tram operator (GAiT). The most frequent events on the Gdansk tram network were collisions and accidents. The internal database, developed by GAiT, allows also to distinguish other events that caused disturbances or stopped the tram traffic. According to the GAiT database, the second most frequent cause of stopping the tram traffic was the loss of power on the overhead contact line resulting from various types of substation failures. Another reason for stopping traffic was the derailment of vehicles, which occurred as a result of incorrect reversing of the vehicle, breakdown of the points or other damage to the track infrastructure. From 2015, there has been a strongly growing number of derailments, which may result from the deteriorating technical condition of tram tracks and their inadequate maintenance. The average time required to restore tram traffic after derailment of the vehicle was 60 minutes. It should be noted that the database received from the operator does not include traffic disturbances caused by a tram car breakdown.

The most common causes of accidents and collisions included: failure to give right of way, failure to adapt speed to traffic conditions, pedestrian entry into the tram path at red traffic light, vehicle entry into the path at red traffic light, incorrect maneuvering while driving. It should be noted that the first of these causes occurred more than twice as often as the second most frequent cause of the analysed events.

It was noted that among the types of event classified as collisions and accidents, the most frequent event was a side collision of vehicles (Fig. 4.12), which took place at junctions where tramway paths intersect with other vehicles. The second most common type of event among collisions and accidents was hitting a pedestrian. Then following: running into the preceding vehicle, which most often occurred between two tram vehicles, and also on non-separated tramway track, on which automobile traffic was allowed; and frontal collisions occurring most often between two tram cars at intersections.

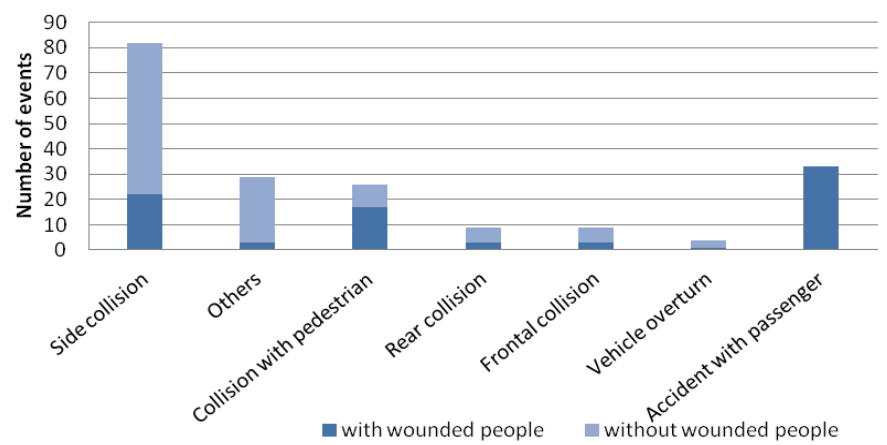

Fig. 1. Number of events in terms of types of event classified as collisions and accidents. 
By far the highest number of collisions were caused by car drivers who account for $77 \%$ of the incidents (Figure 4.13). The distribution of fault between the other road users was about even: pedestrians $-6 \%$, tram drivers $-9 \%$, others $-7 \%$. One percent of all collisions was caused by passenger fault.

Analysing the above data, it is stated that the locations with the highest risk of the occurrence of an event endangering the safety of traffic users are level crossings, intersections and pedestrian crossings. The above was confirmed by the results of surveys carried out among tram drivers on hazard identification on the Gdansk tram network. The respondents had to indicate three points on the map of the Gdansk tram network, which they considered the most dangerous. Then they justified which factors influenced their choice. Figure 2 shows the most common answers:

- possibility of collision with other type of vehicle, a large number of dangerous situations between trams and cars,

- insufficient adhesion (slippery rails) preventing effective braking,

- possibility of collision with pedestrians,

- poor condition of the track and points, which may result in the derailment of the vehicle,

- poor condition of traffic and points control devices, including inefficient points mechanisms,

- lack of protection against derailment or against the effects of derailment (especially on bridges and flyovers),

- lack of visibility, mostly on curves or at intersections.

A large number of indications regarding the possibility of slippage could be caused by the time of the surveys were conducted, i.e. at the end of autumn. It is the time of the year during which the influence of leaves lying on the rails affecting the grip is the greatest and there is the highest number of collisions resulting from the extended braking distance of trams.

Based on the analysis of reports concerning external perpetrators of a collision with trams, it should be acknowledged that tram drivers significantly overestimated the risk of collisions between trams and pedestrians (average share of $11.7 \%$ ) in relation to the risk of collision with passenger cars (average share of 75.4\%). The position of the tram drivers on the issue of danger posed by pedestrians may result from a large number of emergency braking due to the pedestrian's entry onto the tracks. The percentage of indications of reasons for the use of emergency braking systems according to the surveyed drivers is shown in Figure 3. The second reason for over-representation of responses regarding this hazard may be the potential effects of a collision between a tram and pedestrian, which due to the mass disproportion usually ends tragically for a vulnerable event participant.

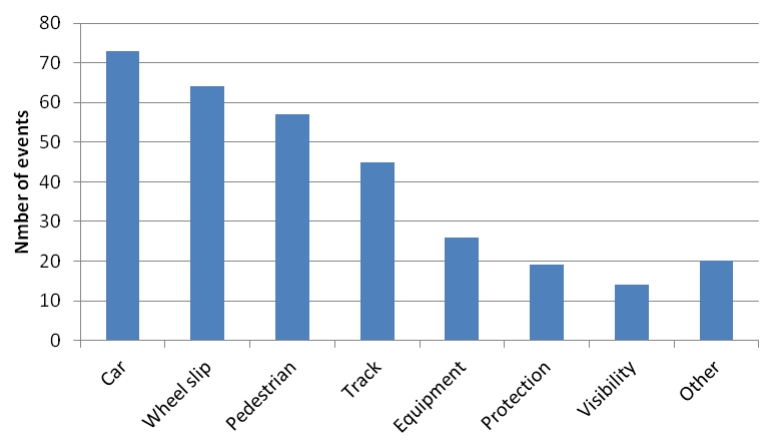

Fig. 2. Hazard sources in particularly dangerous places in Gdansk, according to surveyed tram drivers. 


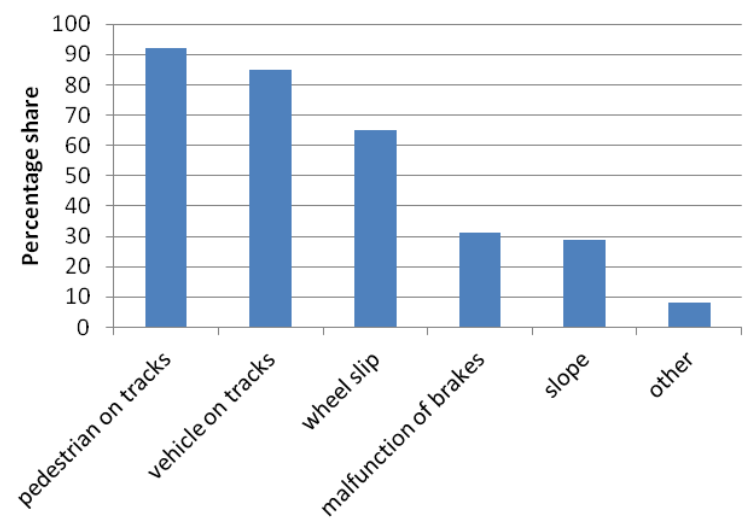

Fig. 3. Summary of indications of reasons for the use of the emergency braking system by tram drivers.

\section{Methodology of limiting existing hazards}

The risk in various shapes and forms exists throughout the life of the object or system. Therefore, activities aiming at risk control and possibly limiting it are inseparably connected with the functionality of the facility.

Occurring hazards must always be considered in relation to the possibility of limiting them. In accordance with the applicable methodology, risk management may be carried out through four stages: elimination or reduction of risk, transfer of risk to another entity or elsewhere, and risk control through systematic actions, diagnostics, contingency plans and corrective actions. The essence of risk management through these four stages is cost. As a rule, each management activity with lower or higher efficiency can be assigned a specific value of expenditure.

In accordance with the principles laid down in the Technical Specifications [18] of Interoperability, four levels of security layers should be considered to achieve the desired low risk:

- The basic layer is to prevent the occurrence of a hazard, that is, to prevent a dangerous situation from occurring.

- If the first layer fails, and a dangerous situation occurs, the measures taken must first of all ensure mitigation of its effects in such a way that there is no hazard to health and life and to reduce the financial consequences of the liquidation of the accident itself.

- The next layer reducing the hazard to health and life are activities related to the evacuation of passengers from the site of an incident or accident as soon as possible.

- In case of a hazard to the health and lives of passengers or bystanders, the last layer to avoid victims is to carry out an effective rescue operation.

The first group of actions to be taken to reduce the probability of an accident are those related to the analysis and improvement of the track infrastructure. Particular attention should be paid to critical elements of tram networks:

- Sections with large profile inclinations (longitudinal);

- Multi rail junctions;

- Curves with radius $\mathrm{R} \leq 50 \mathrm{~m}$;

- Correlation of the plan and profile.

The accelerated degradation of infrastructure elements, in particular rails and sleepers, the condition of which has a direct impact on safety, usually occurs in the sections mentioned above. 
Experience shows that a comprehensive assessment of infrastructure condition must be carried out at least once a year (preferably in the spring).

In addition, it is advisable to carry out visual inspections (once a month) in the tram cab to detect typical faults related to the occurrence of track unevenness, which results in a disturbance of travel comfort. It is advisable to perform direct measurements of tracks (twice a year) $[15,16,19]$ and defectoscopy of rails and their joints. Currently developing highly efficient methods of assessing the condition of track geometry [20,21] are a great field for research on their use to improve safety on tram lines.

The next group of activities that should be clearly separated are activities related to reduction of the number of human errors on the part of tram personnel. On one hand, it is necessary to conduct periodic training and on the other hand enable employees to perform their duties without excessive pressure which may result in reduced concentration on safe driving. In the survey among tram drivers, the question was asked what factors influence the reduction of concentration most significantly. The results of the survey are shown in Figure 4. It shows that the most distracting is the sale of tickets, an activity that can be easily replaced by numerous alternative means of ticket distribution.

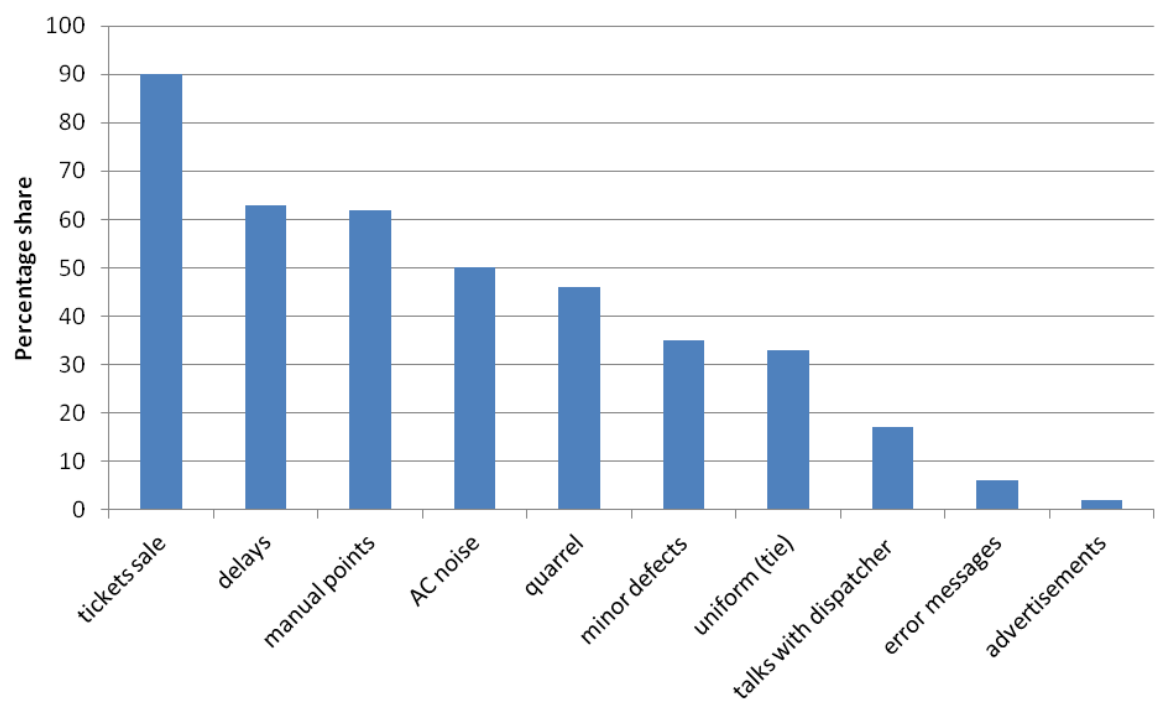

Fig. 4. Share of tram drivers' affirmative responses regarding the factors affecting the reduction of concentration.

\section{Conclusions}

Safety activities should be systemic. From the idea through concepts, design, construction and operation, the project needs to be evaluated in terms of infrastructure safety, organisational safety and safety in traffic engineering.

The basis for the current safety assessment (operational safety) is the inspection process. Inspections of the safety of the infrastructure and traffic organisation in combination with measurements, as a complementary element, allow to gain knowledge about the actual state of safety and make the right decisions regarding repair and maintenance.

One of the key actions to reduce the potential hazard - existing in each of the layers presented in the methodology of limiting the occurrence of hazard - is the periodic training of tram drivers. 
Actions are required not only from the tram operator and infrastructure management. An inseparable element of the safety system is the education of all road users - in the scope related to tram traffic and potential hazards connected with it.

The effectiveness of actions of management of the tram transport system is proven by a low rate of accidents per distance travelled by tramways.

\section{References}

1. Commission Implementing Regulation (EU) No 402/2013 of 30 April 2013 on the common safety method for risk evaluation and assessment and repealing Regulation (EC) No 352/2009 (2013)

2. Commission Directive 2009/149/EC of 27 November 2009 amending Directive 2004/49/EC of the European Parliament and of the Council as regards Common Safety Indicators and common methods to calculate accident costs (2009)

3. Directive 2004/49/EC of The European Parliament and of The Council of 29 April 2004 on safety on the Community's railways and amending Council Directive 95/18/EC and Directive 2001/14/EC (2004)

4. M. Jedynak, S. Młynarski, A. Sowa, Risk and its measures in rail transport (in Polish), Logistyka. 6 (2015)

5. S. Niziński, Elements of exploitation of technical objects (in Polish) (Wydawnictwo Uniwersytetu Warmińsko-Mazurskiego, Olsztyn, 2000)

6. S. Niziński, R. Michalski, Maintenance of vehicles and machines (in Polish) (Instytut Technologii Eksploatacji, Olsztyn, 2007)

7. Z. Smalko, Basics of technical operation of vehicles (in Polish) (Oficyna Wydawnicza Politechniki Warszawskiej, Warszawa, 1998)

8. M. Orczyk, B. Czechyra, E. Wojciechowska, Evaluation of the noise level generated during the traffic phases of selected types of trams (in Polish), Pojazdy Szyn. 2 pp. 44-48 (2009)

9. G. Zając, Research on noise and vibrations in trams (in Polish), Czas. Tech. - Mech. 4 pp. 131-145 (2011)

10. J. Zariczny, S. Grulkowski, The influence of the type of pavement structures on the tram noise level (in Polish), Logistyka. 2 (2011)

11. S. Grulkowski, J. Zariczny, Characteristics of wear, defects and damages of rails in tram tracks (in Polish), Zesz. Nauk. Stowarzyszenia Inżynierów i Tech. Komun. w Krakowie. Ser. Mater. Konf. 2 pp. 31-45 (2015)

12. A. Kadziński, A. Gill, Concept of implementation of the trans-risk method for risk management in tram communication (in Polish), Logistyka. 6 (2011)

13. Ministry of Ecology, Sustainable Development and Energy: Accidentology of tramways, analysis of reported events - year 2013 - evolution 2004 - 2013 (2015)

14. K. Jamroz, Method of risk management in highway engineering. Metoda zarządzania ryzykiem w inżynierii drogowej (Gdansk University of Technology, 2011)

15. PKP Polskie Linie Kolejowe S.A., Instructions on supervision of railway lines Id-7 (in Polish) (Warszawa, 2005)

16. PKP Polskie Linie Kolejowe S.A, Diagnostic instructions for the railway surface Id-8 (in Polish) (Warszawa, 2005)

17. L. Fontaine, M. Novales, D. Bertrand, M. Teixeira, Safety and Operation of Tramways in Interaction with Public Space, Transp. Res. Procedia. 14 pp. 1114-1123 
(2016). doi:10.1016/j.trpro.2016.05.182

18. Commission Decision of 20 December 2007 concerning the technical specification of interoperability relating to 'safety in railway tunnels' in the trans-European conventional and high-speed rail system (2007)

19. PKP Polskie Linie Kolejowe S.A., Instructions on making measurements, tests and assessing the condition of tracks Id-14 (in Polish) (Warszawa, 2005)

20. C. Specht, W. Koc, P. Chrostowski, Computer-aided evaluation of the railway track geometry on the basis of satellite measurements, Open Eng. 6 (2016)

21. C. Specht, W. Koc, L. Smolarek, A. Grządziela, J. Szmagliński, M. Specht, Diagnostics of the tram track shape with the use of the global positioning satellite systems (GPS/Glonass) measurements with a $20 \mathrm{~Hz}$ frequency sampling, J. Vibroengineering. 16 (2014) 